\title{
VIBRATION ANALYSIS OF COMPOSITE LAMINATED PLATES USING HIGHER ORDER THEORY AND LEVY'S SOLUTION
}

\author{
G. S. VIVEK ${ }^{1}$, CH. LAKSHMI TULASI ${ }^{2}$, L. PRAVEEN ${ }^{3} \&$ S. LOKESH ${ }^{4}$ \\ ${ }^{1,4}$ Department of Mechanical Engineering, Institute of Aeronautical Engineering, Dundigal, Hyderabad, India \\ ${ }^{2}$ Department of Mechanical Engineering, Chadalawada Ramanamma Engineering College, Tirupati, Andhra Pradesh, India \\ ${ }^{3}$ Department of Mechanical Engineering, MLR Institute of Technology, Dundigal, Hyderabad, India
}

\begin{abstract}
This paper represents the exploration on the response of a symmetric composite laminated plate. The properties like weight reduction, Fatigue life, wear resistance, Corrosion resistance, Strength Stiffness and Thermal properties can be improved by forming the composite materials. Since vibration and composite material are two focal growing research topics, almost all the structural apparatus subjected to dynamic loading in their working life and vibration affects the working life of the structure. The most commonly used plate theories are Kirchhoff or classical laminated plate theory of thin plate, Mindlin-Reissene or First order shear deformation theory for moderate plates, Levinson's theory or Third order shear deformation theory. CLPT is the simplest plate theory, which the effect of transverse shear deformation that results in the underestimation of transverse deflection of the plate. FSDT is suitable for analyzing moderately thick plates. However, this theory does not satisfy the stress-free boundary conditions on the surface of the plate so it requires shear correction factors for the analysis of the thick plates TSDT is used. The higher order theory of composite laminated plates using levy solution is developed.

KEYWORDS: Laminated Composite Plate, Vibration Analysis, Levy's Solution \& Higher Order Theory
\end{abstract}

Received: Jul 24, 2017; Accepted: Aug 12, 2017; Published: Aug 28, 2017; Paper Id.: IJMPERDOCT20176

\section{INTRODUCTION}

Composite materials are the materials formed by combining two or more materials to achieve better engineering properties. The properties like weight reduction, Fatigue life, wear resistance, Corrosion resistance, Strength Stiffness and Thermal properties can be improved by forming the composite materials. The man made composite materials are from the two materials such as Reinforcement material called Fibres and the Base material called Matrix material. Matrix materials keep the fibres together which acts as load transfer medium between fibres. The Matrix's material have their usual bulk-form properties where as fibres have directionally dependent properties. The load transfer between the matrix material and fibre takes place through shear stress. Some of the application of composite materials are Automotive industry, Marine vessels, Machine elements and Energy application, Consumer durable products, Land transportation, Electrical electronics and communication.

\section{ANALYTICAL SOLUTIONS OF COMPOSITE LAMINATED PLATE USING HIGHER ORDER THEORIES WITH LEVY SOLUTION}

Composite laminates are constructed by stacking several unidirectional layers in a specific sequence of orientation. Hence the failure of the single layer does not give total failure of the laminate. However, it leads to progressive failure of the laminate. Failure mechanism of the composite materials is much more complicated than 
that of the conventional materials due to heterogeneous construction. In case of isotropic materials the failure is observable on the surface of the specimen. In composite due to stacking of several layers failures are confined to one or few layers and may never penetrate to the surface of the laminate. The common mode of failure in composite materials is matrix cracking, fibres breakage and delaminating. A method of accurate analysis is essential for the design and analysis of such a composite laminated plates. Analytical solutions are developed for the first time for anti-symmetric cross ply and angle ply laminated plates based on the higher-order displacement for Mobel-1. This solution method used here is Levy Method with the state space approach, depending on the boundary condition. The levy solutions can be developed for the plate with two opposite edges with simply supported and the remaining two edges having any possible combinations of boundary condition i.e. free simply supported or fixed support. The numerical methods can be used to determine approximate solutions for more general boundary conditions.

\section{LEVY SOLUTIONS FOR CROSS- PLY LAMINATED PLATES}

The levy method can be used to solve the governing equation of a various plate theories for rectangular laminate in which two opposite parallel edges are simply supported and the other two edges can have any boundary condition. In the present work the levy type solution for Vibration of anti-symmetric cross- ply laminates are presented.

A rectangle laminate which has an even number of orthotropic layers is considered. The planar dimension is taken to $b e \mathrm{a}, \mathrm{b}$ and total thickness $\mathrm{h}$. Here it is assumed that the edges $\mathrm{y}=0, \mathrm{~b}$ is simply supported and the other edges can each have arbitrary boundary conditions. The laminate coordinate system $(x, y, z)$ is taken such that $-a / 2 \leq x \leq a / 2,0 \leq y \leq b$, $\mathrm{h} / 2 \leq \mathrm{z} \leq \mathrm{h} / 2$.

The simply supported boundary condition (SS-1) on the edges $\mathrm{y}=0, \mathrm{~b}$ is expressed as:

$$
u_{0}=w_{0}=\theta_{x}=M_{y}=0, u_{0}^{*}=w_{0}^{*}=\theta_{x}^{*}=M_{y}^{*}=0
$$

The simply supported ( $\mathrm{S})$ clamped(C) and free $(\mathrm{F})$ boundary conditions at the edges $\mathrm{x}= \pm \mathrm{a} / 2$ can be expressed as:

Simple supported S: $\mathrm{v}_{0}=\mathrm{w}_{\mathrm{o}}=\theta_{\mathrm{y}}=N_{\mathrm{x}}=M_{\mathrm{x}}=0, \mathrm{v}_{0}{ }^{*}=w_{0}^{*}=\theta_{\mathrm{y}}{ }^{*}=\mathrm{M}_{\mathrm{x}}{ }^{*}=\mathrm{N}_{\mathrm{x}}{ }^{*}=0$.

Clamped C: $u_{0}=v_{0}=w_{0}=\theta_{x}=\theta_{y}=0, u_{0}^{*}=v_{0=}^{*} w_{0}^{*}=\theta_{x}^{*}=\theta_{Y}^{*}=0$

Free F: $M_{x}=M_{x y}=N_{x}=N_{x y}=Q_{x}=0, M_{x}^{*}=M_{x y=}^{*} N_{x}^{*}=N_{x y}^{*}=0$

The generalized displacements expressed as products of undetermined functions and known trigonometric function which has to satisfy the simply supported the boundary conditions at $y=0, b$.

The boundary conditions are satisfied by the following expression:

$$
\begin{aligned}
& u_{0}(x, y, t)=\sum_{m=1}^{\infty} U_{m}(x, t) \sin \beta y \\
& v_{0}(x, y, t)=\sum_{m=1}^{\infty} V_{m}(x, t) \cos \beta y \\
& w_{0}(x, y, t)=\sum_{m=1}^{\infty} W_{m}(x, t) \sin \beta y
\end{aligned}
$$




$$
\begin{aligned}
& \theta_{x}(x, y, t)=\sum_{m=1}^{\infty} X_{m}(x, t) \sin \beta y \\
& \theta_{y}(x, y, t)=\sum_{m=1}^{\infty} Y_{m}(x, t) \cos \beta y \\
& u_{0}^{*}(x, y, t)=\sum_{m=1}^{\infty} U_{m}^{*}(x, t) \sin \beta y \\
& V_{o}^{*}(x, y, t)=\sum_{m=1}^{\infty} V_{m}^{*}(x, t) \cos \beta y \\
& \theta_{x}^{*}(x, y, t)=\sum_{m=1}^{\infty} X_{m}^{*}(x, t) \sin \beta y \\
& \theta_{y}^{*}(x, y, t)=\sum_{m=1}^{\infty} Y_{m}^{*}(x, t) \cos \beta y
\end{aligned}
$$

The mechanical loads are also expanded in single Fourier sine series as:

$$
q(x, y, t)=\sum_{m=1}^{\infty} \sum_{n=1}^{\infty} Q_{m}(x, t) \sin \beta y \quad \text { Where } \beta=m \pi / b
$$

By substituting boundary conditions into the governing equation the differential equations are obtained as:

$$
\begin{aligned}
& A_{11} U_{m, x x}+A_{14} U_{m, x x}^{*}+B_{11} X_{m, x x}+B_{14} X_{m, x x}^{*}=A_{33} \beta^{2} U_{m}+A_{36} \beta^{2} U_{m}^{*}+\left(A_{33}+A_{12}\right) \beta V_{m, x}+\left(A_{15}+\right. \\
& \left.A_{36}\right) \beta V_{m, x}^{*}+B_{33} \beta^{2} X_{m}+B_{36} \beta^{2} X_{m}^{*}+\left(B_{33}+B_{12}\right) \beta Y_{m, x}+\left(B_{15}+B_{36}\right) \beta Y_{m, x}^{*}-I_{1} \omega^{2} U_{m, x x}-I_{2} \omega^{2} X_{m, x x}-I_{3} \omega^{2} U_{m, x x}^{*}- \\
& I_{4} \omega^{2} X_{m, x x}^{*} \\
& A_{33} V_{m, x x}+A_{36} V_{m, x x}^{*}+B_{33} Y_{m, x x}+B_{36} Y_{m, x x}^{*}=-\left(A_{33}+A_{21}\right) \beta U_{m, x x}-\left(A_{24}+A_{36}\right) \beta U_{m, x}^{*}+A_{22} \beta^{2} V_{m}+ \\
& A_{25} \beta^{2} V_{m}^{*}-\left(B_{21}+B_{33}\right) \beta X_{m, x}-\left(B_{24}+B_{36}\right) X_{m, x}^{*}+B_{22} \beta^{2} Y_{m}+B_{25} \beta^{2} Y_{m}^{*}-I_{1} \omega^{2} V_{m, x x}-I_{2} \omega^{2} Y_{m, x x}-I_{3} \omega^{2} V_{m, x x}^{*}- \\
& I_{4} \omega^{2} Y_{m, x x}^{*} \\
& D_{11}^{S} W_{m, x x}=D_{22}^{s} \beta^{2} W_{m}-D_{13}^{S} U_{m, x}^{*}+2 D_{24}^{s} \beta V_{m}-D_{11}^{s} X_{m, x}-3 D_{15}^{s} X_{m, x}^{*}+D_{22}^{s} \beta Y_{m}+3 D_{26}^{s} \beta Y_{m}^{*}-Q-I_{1} \omega^{2} W_{m, x x} \\
& B_{11} U_{m, x x}+B_{14} U_{m, x x}^{*}+D_{11} X_{m, x x}+D_{14} X_{m, x x}^{*}=B_{33} \beta^{2} U_{m}+\left(B_{36} \beta^{2}+2 D_{13}^{s}\right) U_{m}^{*}+\left(B_{33}+B_{12}\right) \beta V_{m, x}+\left(B_{15}+\right. \\
& \left.B_{36}\right) \beta V_{m, x}^{*}+D_{11}^{s} W_{m, x}+\left(D_{33} \beta^{2}+D_{11}^{s}\right) X_{m}+\left(D_{36} \beta^{2}+3 D_{15}^{S}\right) X_{m}^{*}+\left(D_{33}+D_{12}\right) \beta Y_{m, x}+\left(D_{15}+D_{36}\right) \beta Y_{m, x}^{*}- \\
& I_{2} \omega^{2} U_{m, x x}-I_{3} \omega^{2} X_{m, x x}-I_{4} \omega^{2} U_{m, x x}^{*}-I_{5} \omega^{2} X_{m, x x}^{*} \\
& \mathrm{~B}_{33} \mathrm{~V}_{\mathrm{m}, \mathrm{x}}+\mathrm{B}_{36} \mathrm{~V}_{\mathrm{m}, \mathrm{xx}}^{*}+\mathrm{D}_{33} \mathrm{Y}_{\mathrm{m}, \mathrm{xx}}+\mathrm{D}_{36} \\
& =-\left(B_{23}+B_{21}\right) \beta U_{m, x}-\left(B_{24}+B_{36}\right) \beta U_{m, x}^{*}+B_{22} \beta^{2} V_{m}+\left(B_{25} \beta^{2}+2 D_{24}^{s} V_{m}^{*}+D_{22}^{s} \beta W_{m}\right. \\
& -\left(D_{21}+D_{33}\right) \beta X_{m, x}-\left(D_{24}+D_{36}\right) X_{m, x}^{*}+\left(D_{22} \beta^{2}+D_{22}^{s}\right) Y_{m}+\left(D_{25} \beta^{2}+3 D_{26}^{s}\right) Y_{m}^{*}-I_{2} \omega^{2} V_{m, x x} \\
& -\mathrm{I}_{2} \omega^{2} \mathrm{Y}_{\mathrm{m}, \mathrm{xx}}-\mathrm{I}_{3} \omega^{2} \mathrm{~V}_{\mathrm{m}, \mathrm{xx}}^{*}-\mathrm{I}_{4} \omega^{2} \mathrm{Y}_{\mathrm{m}, \mathrm{xx}}^{*}
\end{aligned}
$$




$$
\begin{gathered}
A_{41} U_{m, x x}+A_{44} U_{m, x x}^{*}+B_{44} X_{m, x x}+B_{44} X_{m, x x}^{*}=A_{63} \beta^{2} U_{m}+\left(A_{66} \beta^{2}+4 D_{33}^{s}\right) U_{m}^{*}+\left(A_{42}+A_{63}\right) \beta V_{m, x}+ \\
\left(A_{45}+A_{66}\right) \beta V_{m, x}^{*}+2 D_{31}^{s} W_{m, x}+\left(B_{36} \beta^{2}+2 D_{31}^{s}\right) X_{m}+\left(B_{66} \beta^{2}+6 D_{35}^{s}\right) X_{m}^{*}+\left(B_{42}+B_{63}\right) \beta Y_{m, x}+\left(B_{45}+B_{66}\right) \beta Y_{m, x}^{*}- \\
I_{3} \omega^{2} U_{m, x x}-I_{4} \omega^{2} X_{m, x x}-I_{5} \omega^{2} U_{m, x x}^{*}-I_{6} \omega^{2} X_{m, x x}^{*} \\
A_{63} V_{m, x x}+A_{66} V_{m, x x}^{*}+B_{63} Y_{m, x x}+B_{66} Y_{m, x x}^{*}=-\left(A_{51}+A_{63}\right) \beta U_{m, x}-\left(A_{54}+A_{66}\right) \beta U_{m, x}^{*}+A_{52} \beta^{2} V_{m}+ \\
\left(A_{25} \beta^{2}+4 D_{44}^{s}\right) V_{m}^{*}+2 D_{42}^{s} \beta W_{m}-\left(B_{51}+B_{63}\right) \beta X_{m, x}-\left(B_{54}+B_{66}\right) X_{m, x}^{*}+\left(B_{52} \beta^{2}+2 D_{42}^{s}\right) Y_{m}+\left(B_{25} \beta^{2}+6 D_{46}^{s}\right) Y_{m}^{*}- \\
I_{3} \omega^{2} V_{m, x x}-I_{4} \omega^{2} X_{m, x x}-I_{5} \omega^{2} V_{m, x x}^{*}-I_{6} \omega^{2} X_{m, x x}^{*} \\
B_{14} U_{m, x x}+B_{44} U_{m, x x}^{*}+D_{41} X_{m, x x}+D_{44} X_{m, x x}^{*}=B_{36} \beta^{2} U_{m}+\left(B_{66} \beta^{2}+9 D_{55}^{s}\right) U_{m}^{*}+\left(B_{24}+B_{36}\right) \beta V_{m, x}+ \\
\left(B_{54}+B_{66}\right) \beta V_{m, x}^{*}+3 D_{31}^{s} W_{m, x}+\left(D_{63} \beta^{2}+3 D_{51}^{s}\right) X_{m}+\left(D_{66} \beta^{2}+9 D_{55}^{s}\right) X_{m}^{*}+\left(D_{42}+D_{12}\right) \beta Y_{m, x}+\left(D_{45}+D_{66}\right) \beta Y_{m, x}^{*}- \\
I_{4} \omega^{2} U_{m, x x}-I_{5} \omega^{2} X_{m, x x}-\omega^{2} U_{m, x x}^{*}-I_{7} \omega^{2} X_{m, x x}^{*} \\
B_{36} V_{m, x x}+B_{66} V_{m, x x}^{*}+D_{63} Y_{m, x x}+D_{66} Y_{m, x x}^{*}=-\left(B_{15}+B_{36}\right) \beta U_{m, x}-\left(B_{45}+B_{66}\right) \beta U_{m, x}^{*}+B_{25} \beta^{2} V_{m}+ \\
\left(B_{55} \beta^{2}+6 D_{64}^{s}\right) V_{m}^{*}+3 D_{62}^{s} \beta W_{m}-\left(D_{51}+D_{63}\right) \beta X_{m, x}-\left(D_{54}+D_{66}\right) X_{m, x}^{*}+\left(D_{25} \beta^{2}+3 D_{62}^{s}\right) Y_{m}+\left(D_{55} \beta^{2}+9 D_{66}^{s}\right) Y_{m}^{*}- \\
I_{4} \omega^{2} V_{m, x x}-I_{4} \omega^{2} X_{m, x x}-I_{5} \omega^{2} V_{m, x x}^{*}-I_{7} \omega^{2} X_{m, x x}^{*}
\end{gathered}
$$

Levy's Solutions are Calculated by Rewriting the Equation in the Matrix form as

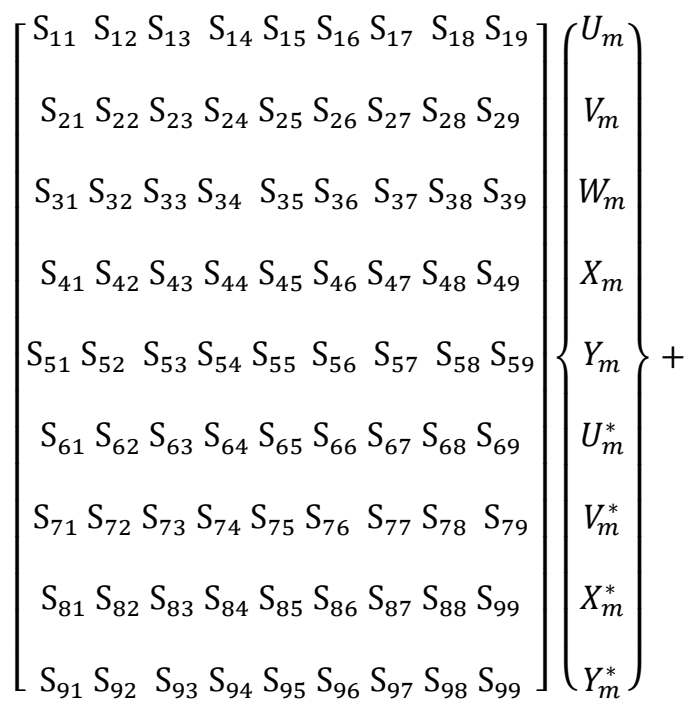

$$
\begin{aligned}
& {\left[\begin{array}{ccccccccc}
m_{11} & 0 & 0 & m_{14} & 0 & m_{16} & 0 & m_{18} & 0 \\
0 & m_{22} & 0 & 0 & m_{25} & 0 & m_{27} & 0 & m_{29} \\
0 & 0 & m_{33} & 0 & 0 & 0 & 0 & 0 & 0 \\
m_{41} & 0 & 0 & m_{44} & 0 & m_{46} & 0 & m_{48} & 0 \\
0 & m_{52} & 0 & 0 & m_{55} & 0 & m_{57} & 0 & m_{59} \\
m_{61} & 0 & 0 & m_{64} & 0 & m_{66} & 0 & m_{68} & 0 \\
0 & m_{72} & 0 & 0 & m_{75} & 0 & m_{77} & 0 & m_{79} \\
m_{81} & 0 & 0 & m_{84} & 0 & m_{86} & 0 & m_{88} & 0 \\
0 & m_{92} & 0 & 0 & m_{95} & 0 & m_{97} & 0 & m_{99}
\end{array}\right]\left\{\begin{array}{c}
U_{m} \\
V_{m} \\
W_{m} \\
X_{m} \\
Y_{m} \\
U_{m}^{*} \\
V_{m}^{*} \\
X_{m}^{*} \\
Y_{m}^{*}
\end{array}\right\}=\left\{\begin{array}{c}
0 \\
0 \\
Q_{m} \\
0 \\
0 \\
0 \\
0 \\
0 \\
0
\end{array}\right\}}
\end{aligned}
$$

\section{FREE VIBRATION ANALYSIS OF SIMPLY SUPPORTED ANTI-SYMMETRIC CROSS-PLY}

\section{LAMINATED PLATES}

For free vibration set the mechanical loads to zero and assume periodic solution of the form:

$$
U_{m n}(t)=U_{m n} e^{-i \omega t}
$$




$$
\begin{aligned}
& V_{m n}(t)=V_{m n} e^{-i \omega t} \\
& W_{m n}(t)=W_{m n} e^{-i \omega t} \\
& X_{m n}(t)=X_{m n} e^{-i \omega t} \\
& Y_{m n}(t)=Y_{m n} e^{-i \omega t}
\end{aligned}
$$

For free vibration, reduces to the eigen values as

$$
\left([S]-\omega^{2}[M]\right)\{\Delta\}
$$

Where

$\Delta=U_{m n}, V_{m n}, W_{m n}, X_{m n}, Y_{m n}$

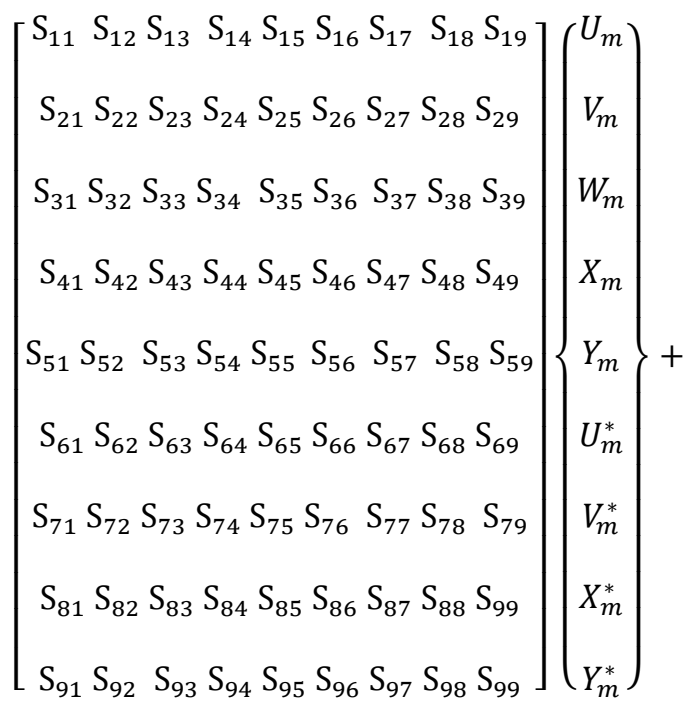

$$
\left[\begin{array}{ccccccccc}
m_{11} & 0 & 0 & m_{14} & 0 & m_{16} & 0 & m_{18} & 0 \\
0 & m_{22} & 0 & 0 & m_{25} & 0 & m_{27} & 0 & m_{29} \\
0 & 0 & m_{33} & 0 & 0 & 0 & 0 & 0 & 0 \\
m_{41} & 0 & 0 & m_{44} & 0 & m_{46} & 0 & m_{48} & 0 \\
0 & m_{52} & 0 & 0 & m_{55} & 0 & m_{57} & 0 & m_{59} \\
m_{61} & 0 & 0 & m_{64} & 0 & m_{66} & 0 & m_{68} & 0 \\
0 & m_{72} & 0 & 0 & m_{75} & 0 & m_{77} & 0 & m_{79} \\
m_{81} & 0 & 0 & m_{84} & 0 & m_{86} & 0 & m_{88} & 0 \\
0 & m_{92} & 0 & 0 & m_{95} & 0 & m_{97} & 0 & m_{99}
\end{array}\right]\left\{\begin{array}{c}
U_{m} \\
V_{m} \\
W_{m} \\
X_{m} \\
Y_{m} \\
U_{m}^{*} \\
V_{m}^{*} \\
X_{m}^{*} \\
Y_{m}^{*}
\end{array}\right\}
$$

For a non trivial solution, $\{\Delta\} \neq 0$, the determent of the coefficient matrix should be zero, which yields the characteristic equation:

$$
[\mathrm{S}]-\lambda[\mathrm{M}]=0
$$

Where $\lambda=\omega^{2}$ Is the Eigen value.

The real positive roots give the square of the natural frequency $\omega_{m, n}$ Associated with mode (m, $\mathrm{n}$ ). The smallest of the equation is called the fundamental natural frequency.

\section{RESULTS AND DISCUSSIONS}

Numerical computations are carried out for the free undamped transverse vibration analysis of laminated 
composite plate. The effect of material orthotropy, transverse shear deformation, the ratio of span to thickness, coupling between stretching and bending and the number of lamina in the laminate on the frequencies are investigated. The material properties used for each lamina of the laminated composite plate are as follows:

\section{Elastic Layer (Graphite/Epoxy):}

Modular ratio $\mathrm{E}_{1} / \mathrm{E}_{2}=3 \mathrm{~N} / \mathrm{cm}^{2}$

$\mathrm{G}_{12}=G_{13}=0.6 E_{2} \mathrm{G}_{23}=0.5 E_{2}$

Young's Modulus $\mathrm{E}_{2}=\mathrm{E}_{3}=10^{6} \mathrm{~N} / \mathrm{cm}^{2}$

$\mu_{12}=\mu_{23}=\mu_{13}=0.25$

The plane stress reduced elastic constant of the $L^{\text {th }}$ laminates are:

$$
\begin{aligned}
& C_{11}=3.075 \times 10^{6} \\
& C_{12}=0.0300 \times 10^{6} \\
& C_{22}=0.9975 \times 10^{6} \\
& C_{33}=0.6 \times 10^{6} \\
& C_{44}=0.5 \times 10^{6} \\
& C_{55}=0.6 \times 10^{6}
\end{aligned}
$$

The natural frequencies of general rectangular composites are presented here in non-dimensional form using the following multiplier $\varpi=\left(\omega a^{2} / h\right) \sqrt{\rho / E_{2}}$.

A simply supported laminated cross-ply composite plate of is considered for comparisons of fundamental natural frequencies. The set of orthotropic material properties by considering $E_{1} / E_{2}=$ open and the results are presented in Table 1. The numerical values of non-dimensioned fundamental frequencies obtained using the levy method for various boundary conditions are presented in the tables for anti-symmetric cross-ply laminated plates. The fundamental frequencies increase with increasing orthotropy $E_{1} / E_{2}$ as well as the number of layers.

\section{The Effect of Orthotropy, Number of Layers, Side Thickness Ratio, Shear Deformation and Coupling on Fundamental Natural Frequency}

- Figure 1 shows the effect of modulus ratio is more significant and there is a difference between $2,4,6$ and 8 layered solution increases with moduli ratio. For an example the 4-layered laminated plate has a vibration frequency about $20 \%$ lower than those 6 and 8 layered plates with the same total thickness at a higher modulus ratio (E1/E2). It is also observed that with an increase in the number of layers the frequencies approach those of orthotropic plates.

- Figure 2 shows the effect of fundamental natural frequencies of the anti-symmetric cross-ply laminates is shown as a function of side to side thickness ratio and number layers are plotted and it is shown that the shear deformation effect is increasing significantly on the vibration of the plates. The effect of shear deformation 
decreases with increasing values of a/h which is lesser than of layer 4,6 and 8

- Figure 3 shows the effect of non-dimensioned fundamental frequencies for the anti-symmetric cross-ply laminated plates as a function of the number of layers and side to thickness ratio $(\mathrm{a} / \mathrm{h})$. As the number of layers increases without changing the total thickness, thus increase the fundamental frequencies.

- Figure 4 shows the effect of thickness and the number of layers on the non-dimensioned fundamental frequencies for the layer 2, 4, 6, and 8 anti-symmetric cross-ply. It is also observed that the responses of the layered 2, 4, 6 and 8 laminate decreases in bending coupling and increases the fundamental frequencies.

- Figure 5 shows the effect of the plots of fundamental frequencies is a function of aspect ratio (a/b) and side to thickness ratio $(\mathrm{a} / \mathrm{h})$ for anti-symmetric cross-ply laminated composite plates. It is found that the percentage error is about $20 \%$ of the cross-ply laminated plates. This percentage error decreased with an increase in the number of layers.

- Figure 6 shows the effect of increasing the fundamental frequency. And it is noted that the fundamental frequency of the two layered plates is about $20 \%$ lower than that of the 8 layered laminate.

Table1: Non-Dimensionalized fundamental Frequencies $\omega=\left(\frac{\omega b^{2}}{h}\right) \sqrt{\rho / E_{2}}$ for a simply Supported Anti-Symmetric Cross-ply Laminated Plate for $\mathrm{a} / \mathrm{h}=5$

\begin{tabular}{|l|l|c|c|c|c|c|}
\hline $\begin{array}{c}\text { No. of } \\
\text { Layers }\end{array}$ & Sources & \multicolumn{5}{|c|}{$\mathbf{E}_{\mathbf{1}} / \mathbf{E}_{\mathbf{2}}$} \\
\hline & & $\mathbf{3}$ & $\mathbf{1 0}$ & $\mathbf{2 0}$ & $\mathbf{3 0}$ & $\mathbf{4 0}$ \\
\hline$[0 / 90] 2$ & Present & 6.262 & 6.9597 & 7.7015 & 8.2670 & 8.7169 \\
\hline$[0 / 90] 4$ & Present & 6.4952 & 8.1279 & 9.4480 & 10.2553 & 10.8058 \\
\hline$[0 / 90] 6$ & Present & 6.5527 & 8.3666 & 9.8163 & 10.6954 & 11.2909 \\
\hline$[0 / 90] 8$ & Present & 6.5824 & 8.4972 & 10.0257 & 10.9545 & 11.5859 \\
\hline$[0 / 90] 10$ & Present & 6.6594 & 8.5688 & 10.5246 & 11.0269 & 11.8659 \\
\hline
\end{tabular}

Table 2: Non-Dimensionalized fundamental Frequencies $\omega=\left(\frac{\omega b^{2}}{h}\right) \sqrt{\rho / E_{2}}$ for a Simply Supported Anti-Symmetric Cross-Ply Square Laminated Plate for $E_{1} / E_{2}=40$

\begin{tabular}{|l|c|l|c|c|c|c|}
\hline \multirow{2}{*}{$\mathbf{a} / \mathbf{b}$} & \multirow{2}{*}{$\begin{array}{c}\text { No. of } \\
\text { layers }\end{array}$} & \multirow{2}{*}{ Source } & \multicolumn{4}{|c|}{$\mathbf{a} / \mathbf{h}$} \\
\cline { 4 - 7 } & & $\mathbf{1 0}$ & $\mathbf{2 0}$ & $\mathbf{3 0}$ & $\mathbf{4 0}$ \\
\hline \multirow{2}{*}{1} & $0 / 90$ & Present & 10.3923 & 11.3137 & 10.3871 & 11.3137 \\
\cline { 2 - 7 } & $(0 / 90) 2$ & Present & 15.6205 & 17.4356 & 18.2884 & 18.5903 \\
\hline \multirow{2}{*}{2} & $0 / 90$ & Present & 25.1396 & 29.3938 & 30.5788 & 30.9838 \\
\cline { 2 - 7 } & $(0 / 90) 4$ & Present & 34.1760 & 45.4313 & 49.0876 & 50.59654 \\
\hline \multirow{2}{*}{3} & $0 / 90$ & Present & 44.6766 & 58.2409 & 62.6105 & 64.4981 \\
\cline { 2 - 7 } & $(0 / 90) 6$ & Present & 55.9285 & 84.6640 & 97.6241 & 104.0000 \\
\hline \multirow{2}{*}{4} & $0 / 90$ & Present & 66.2419 & 94.4880 & 105.7583 & 110.8513 \\
\cline { 2 - 7 } & $(0 / 90) 8$ & Present & 78.7401 & 129.3677 & 157.7561 & 173.4359 \\
\hline \multirow{2}{*}{5} & $0 / 90$ & Present & 84.8065 & 148.9654 & 175.2316 & 185.2365 \\
\cline { 2 - 7 } & {$[0 / 90] 10$} & Present & 98.3216 & 168.2546 & 195.5642 & 196.5469 \\
\hline
\end{tabular}

Table 3: Variation of Non Dimensionalized Frequencies $\varpi=\left(\frac{\omega b^{2}}{h}\right) \sqrt{\rho / E_{2}}$ with $\mathbf{a} / \mathbf{h}$ for a Simply Supported Cross-Ply Square Laminated Plate $E_{1} / E_{2}=40$

\begin{tabular}{|c|c|c|c|c|c|c|}
\hline $\begin{array}{c}\text { No. of } \\
\text { Layers }\end{array}$ & Source & $\mathbf{2}$ & $\mathbf{4}$ & $\mathbf{1 0}$ & $\mathbf{2 0}$ & $\mathbf{5 0}$ \\
\hline$(0 / 90) 2$ & Present & 5.0881 & 7.9091 & 10.412 & 11.0733 & 11.2999 \\
\hline
\end{tabular}




\begin{tabular}{|c|c|c|c|c|c|c|}
\hline$(0 / 90) 4$ & Present & 5.404 & 9.2870 & 15.1058 & 17.6570 & 18.673 \\
\hline$(0 / 90) 6$ & Present & 6.321 & 10.654 & 17.236 & 19.612 & 20.256 \\
\hline \multicolumn{7}{|c|}{ Table 3: Contd., } \\
\hline$(0 / 90) 8$ & Present & 8.654 & 12.359 & 19.236 & 21.756 & 22.365 \\
\hline$(0 / 90) 10$ & Present & 10.369 & 14.365 & 21.489 & 23.659 & 25.265 \\
\hline
\end{tabular}

Table 4: Effect of Degree of Orthotropy of the Individual Layers on the Dimensionless Fundamental Frequenc of Simply Supported Anti Symmetric cross-Ply Square Laminated a/h=5 $\varpi=\left(\frac{\omega b^{2}}{h}\right) \sqrt{\rho / E_{2}}$

\begin{tabular}{|c|l|c|c|c|c|c|}
\hline \multirow{2}{*}{$\begin{array}{c}\text { No. of } \\
\text { Layers }\end{array}$} & \multirow{2}{*}{ Sources } & \multicolumn{5}{|c|}{$\mathbf{E}_{\mathbf{1}} / \mathbf{E}_{\mathbf{2}}$} \\
\cline { 3 - 7 } & $\mathbf{3}$ & $\mathbf{1 0}$ & $\mathbf{2 0}$ & $\mathbf{3 0}$ & $\mathbf{4 0}$ \\
\hline$[0 / 90] 2$ & Present & 2.7483 & 2.7775 & 2.8082 & 2.8328 & 2.8533 \\
\hline$[0 / 90] 4$ & Present & 2.7601 & 2.8289 & 2.8875 & 2.9247 & 2.9508 \\
\hline$[0 / 90] 6$ & Present & 2.7622 & 2.836 & 2.8977 & 2.9353 & 2.9610 \\
\hline$[0 / 90] 8$ & Present & 2.7633 & 2.8405 & 2.9025 & 2.9402 & 2.9657 \\
\hline$[0 / 90] 10$ & Present & 2.7722 & 2.9302 & 2.9825 & 2.9524 & 2.9765 \\
\hline
\end{tabular}

Table 5: Effect of Side-to-Thickness Ratio on the Non-Dimensional Frequencies $\omega=\left(\frac{\omega b^{2}}{h}\right) \sqrt{\rho / E_{2}}$ of Anti-Symmteric Cross-Ply Square Plates

\begin{tabular}{|c|c|l|c|c|c|c|c|}
\hline $\begin{array}{c}\text { No. of } \\
\text { Layers }\end{array}$ & $\mathbf{a} / \mathbf{h}$ & Source & FS & FC & SS & SC & CC \\
\hline \multirow{2}{*}{2} & 5 & Present & 6.387 & 6.836 & 9.087 & 10.393 & 11.89 \\
\cline { 2 - 8 } & 10 & Present & 7.277 & 7.810 & 10.568 & 12.87 & 15.709 \\
\hline \multirow{3}{*}{4} & 5 & Present & 8.288 & 8.966 & 11.673 & 12.514 & 13.568 \\
\cline { 2 - 8 } & 10 & Present & 11.074 & 11.863 & 15.771 & 18.175 & 20.831 \\
\hline \multirow{2}{*}{6} & 5 & Present & 13.126 & 13.999 & 17.9771 & 20.359 & 22.936 \\
\cline { 2 - 8 } & 10 & present & 15.259 & 15.990 & 19.269 & 22.987 & 25.369 \\
\hline \multirow{3}{*}{8} & 5 & Present & 16.269 & 17.489 & 21.874 & 23.658 & 29.269 \\
\cline { 2 - 8 } 10 & Present & 18.329 & 19.359 & 23.148 & 25.489 & 30.569 \\
\hline \multirow{3}{*}{10} & 5 & Present & 19.265 & 21.369 & 26.159 & 27.369 & 32.159 \\
\cline { 2 - 8 } & 10 & Present & 21.367 & 23.698 & 28.364 & 29.148 & 34.197 \\
\hline
\end{tabular}

Table 6 Effect of the Orthotropic Ratio and Number of Layers on the Non-Dimensional Fundamental Frequency of Anti-Symmetric Cross-Ply Square Laminated at $\mathbf{a} / \mathbf{h}=10$ for Various Boundary Condition

\begin{tabular}{|c|c|c|c|c|c|c|c|}
\hline $\begin{array}{c}\text { No. Of } \\
\text { layer }\end{array}$ & E1/E2 & Source & FS & FC & SS & SC & CC \\
\hline \multirow{4}{*}{8} & 2 & Present & 7.037 & 10.746 & 12.245 & 6.310 & 7.374 \\
\cline { 2 - 8 } & 10 & Present & 8.11 & 12.368 & 15.395 & 7.589 & 8.521 \\
\cline { 2 - 8 } & 20 & Present & 8.954 & 13.689 & 15.99 & 8.525 & 9.410 \\
\cline { 2 - 8 } & 30 & Present & 9.647 & 13.761 & 117.216 & 9.274 & 10.139 \\
\cline { 2 - 8 } & 40 & Present & 10.249 & 15.674 & 18.218 & 9.951 & 10.772 \\
\hline \multirow{4}{*}{10} & 2 & Present & 8.157 & 11.959 & 13.517 & 7.452 & 8.5 \\
\cline { 2 - 8 } & 10 & Present & 10.692 & 15.917 & 18.350 & 10.308 & 11.177 \\
\cline { 2 - 8 } & 20 & Present & 12.634 & 18.762 & 21.354 & 12.364 & 13.236 \\
\cline { 2 - 8 } & 30 & Present & 14.012 & 20.653 & 24.188 & 13.78 & 17.711 \\
\cline { 2 - 8 } & 40 & Present & 15.077 & 22.043 & 26.471 & 14.896 & 16.858 \\
\hline
\end{tabular}

Table 7 Effect of Side-to-Thickness Ratio on the Dimensionless Frequencies, $\varpi=\left(\frac{\omega b^{2}}{h}\right) \sqrt{\rho / E_{2}}$ of Anti symmetric Cross-Ply Square Plates

\begin{tabular}{|c|c|l|c|c|c|c|c|}
\hline $\begin{array}{c}\text { No. of } \\
\text { Layer }\end{array}$ & $\mathbf{a} / \mathbf{h}$ & \multicolumn{1}{|c|}{ Source } & FS & FC & SS & SC & CC \\
\hline \multirow{2}{*}{8} & 5 & Present & 6.387 & 6.836 & 9.087 & 10.393 & 11.89 \\
\cline { 2 - 8 } & 10 & Present & 7.277 & 7.810 & 10.568 & 12.87 & 15.709 \\
\hline & 5 & Present & 8.288 & 8.966 & 11.673 & 12.514 & 13.568 \\
\hline
\end{tabular}




\begin{tabular}{|l|l|l|l|l|l|l|l|}
\hline 10 & 10 & Present & 11.074 & 11.863 & 15.771 & 18.175 & 20.831 \\
\hline
\end{tabular}

Table 8: Non Dimensionalized Centre Deflection (ש) of Ant Symmetric Cross-Ply Square Plates with Various Boundary Conditions

\begin{tabular}{|c|c|l|c|c|c|c|c|}
\hline $\begin{array}{c}\text { No. of } \\
\text { Layers }\end{array}$ & $\mathbf{a} / \mathbf{h}$ & Source & FS & FC & SS & SC & CC \\
\hline \multirow{2}{*}{8} & 5 & Present & 2.213 & 1.739 & 1.668 & 1.337 & 1.090 \\
\cline { 2 - 8 } & 10 & Present & 1.660 & 1.189 & 1.219 & 0.850 & 0.619 \\
\hline \multirow{2}{*}{10} & 5 & Present & 1.458 & 1.219 & 1.134 & 1.009 & 0.883 \\
\cline { 2 - 8 } & 10 & Present & 0.809 & 0.609 & 0.619 & 0.479 & 0.379 \\
\hline
\end{tabular}

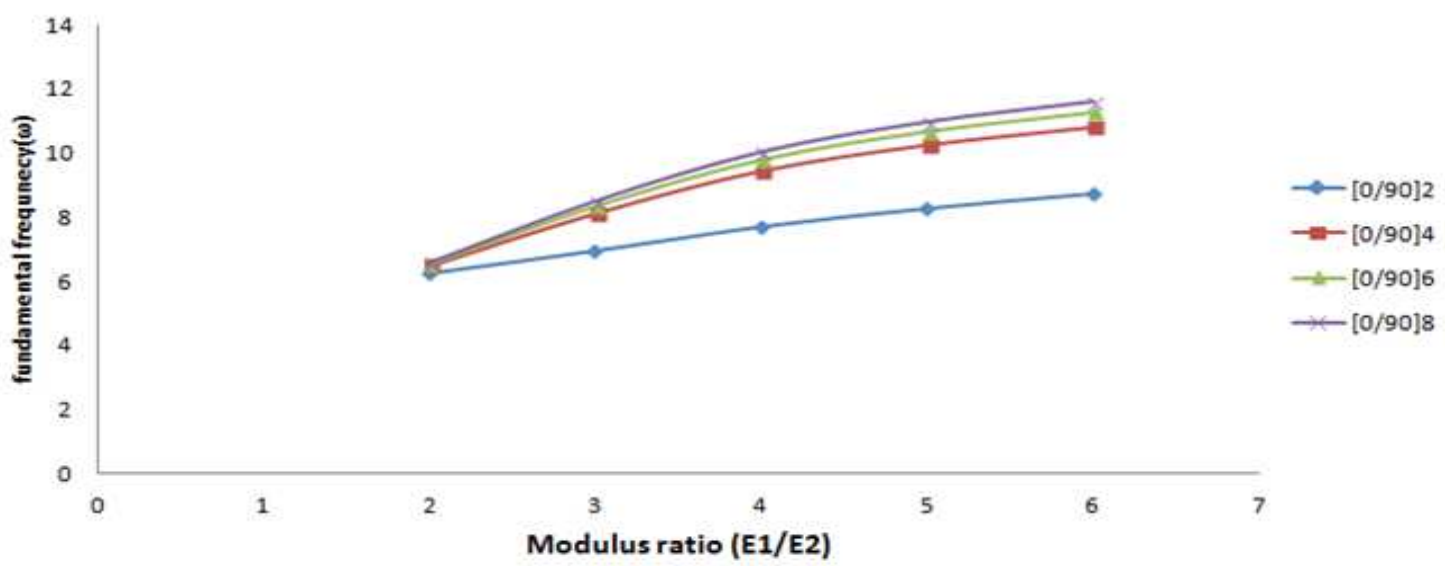

Figure 1: Non-Dimensional Fundamental Frequency $(\omega)$ Vs Modulus Ration $\left(E_{1} / E_{2}\right)$ for Simply Supported Anti-Symmetric Cross-Play Laminated Square Plate

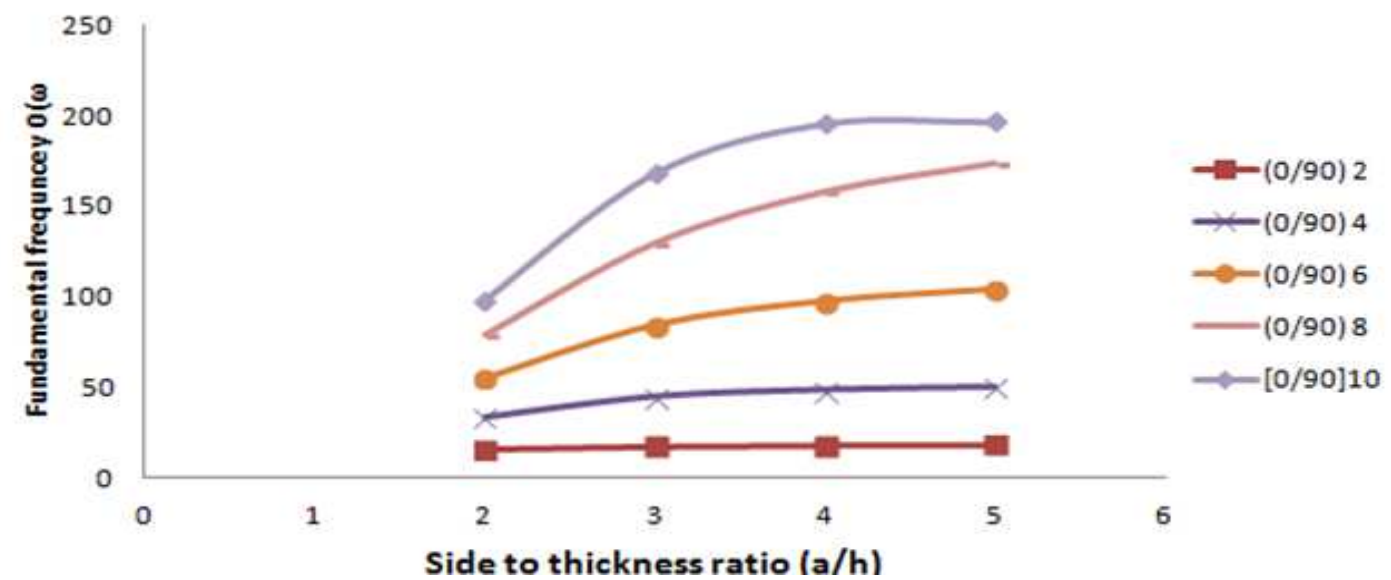

Figure 2: Non-Dimensionalized Fundamental Frequency ( $\Omega$ ) Vs Side to Thickness Ratio (A/H) for Simply Supported Anti-Symmetric Cross-Play Laminated Square Plate 


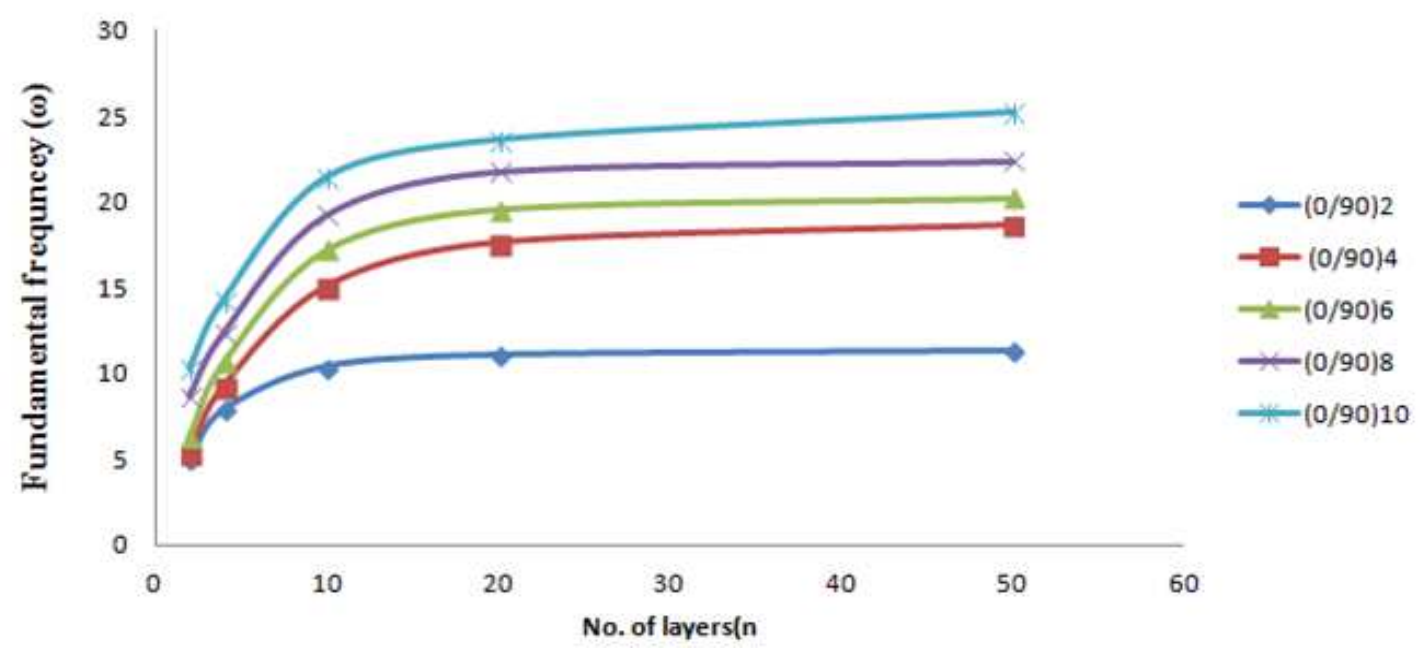

Figure 3: Non-Dimensionalized Fundamental Frequency $(\Omega)$ Vs Number of Layers $(\mathrm{N})$ for Simply Supported Anti-Symmetric Cross-Play Laminated Square Plate

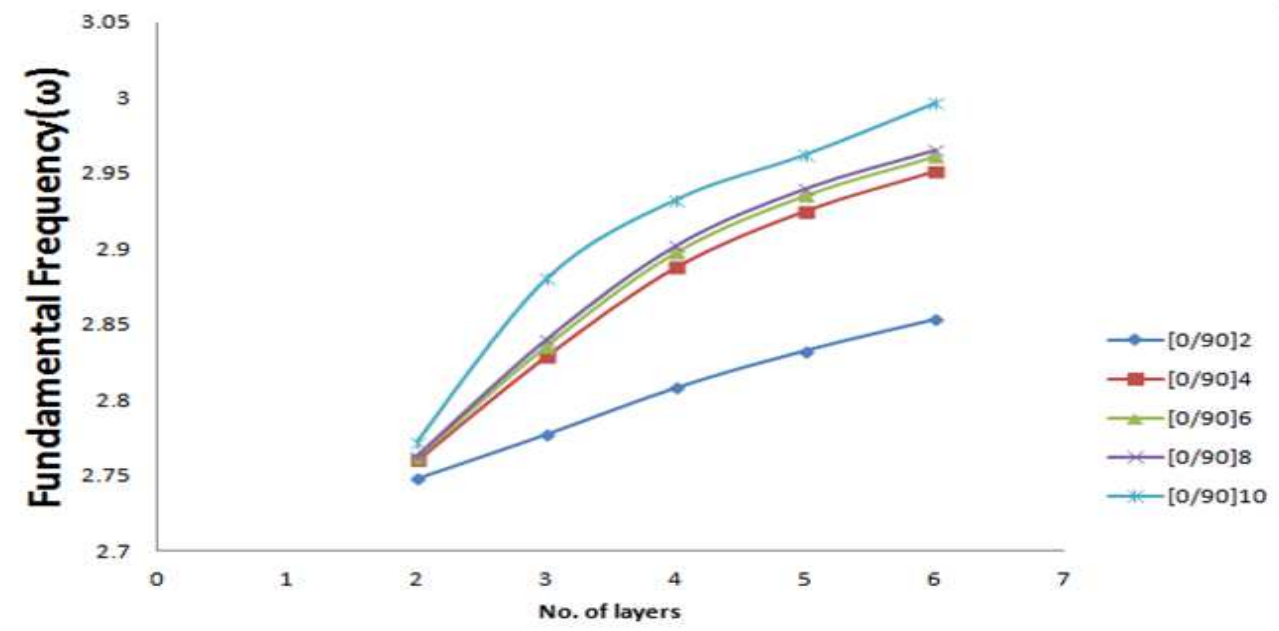

Figure 4: Non-Dimensionalized Fundamental Frequency ( $\Omega$ ) Vs Plate Aspect Ratio (A/B) for Simply Supported Anti-Symmetric Cross-Play Laminated Square Plate

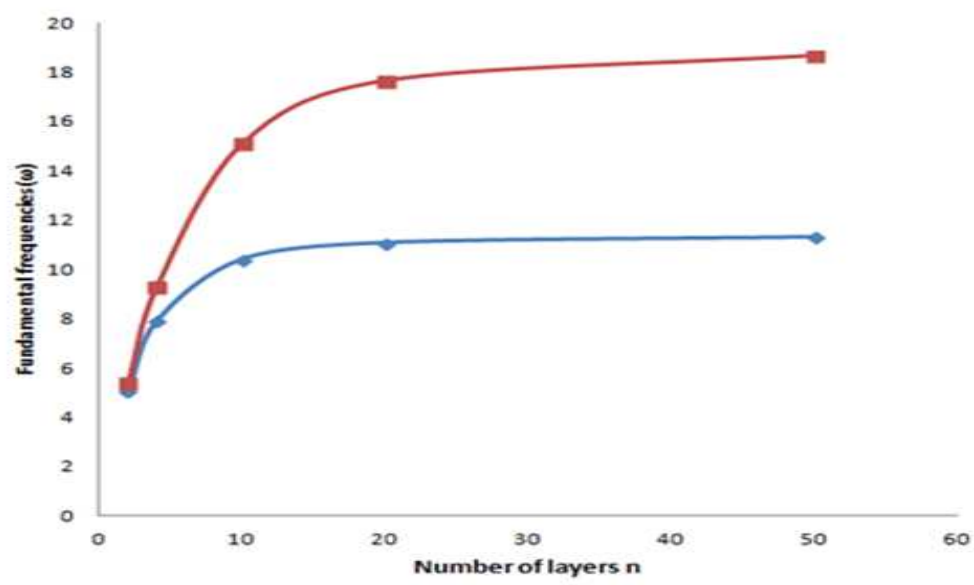

Figure 5: Non-Dimensionalized Fundamental Frequency $(\Omega)$ Vs Number of Layers $(N)$ for Simply Supported Anti-Symmetric Cross-Play Laminated Square Plate 


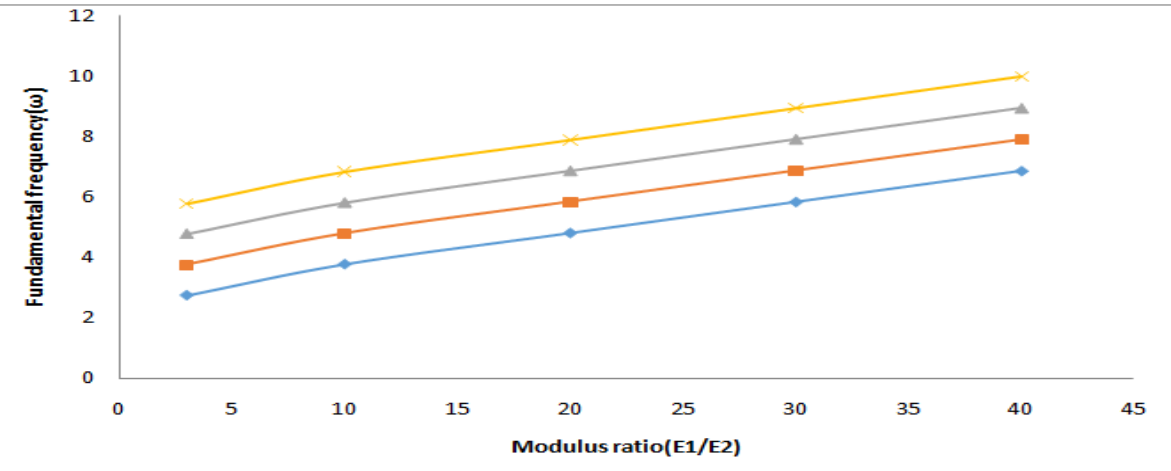

Figure 6: Non-Dimensionalized Fundamental Frequency $(\Omega) \operatorname{Vs}$ Modulus Ratio $\left(\mathbf{E}_{1} / \mathbf{E}_{2}\right)$ for Simply Supported Anti-Symmetric Cross-Play Laminated Square Plate

\section{CONCLUSIONS}

The following conclusions are drawn from the result of the investigations on composite anti-symmetric cross-ply laminated plate using higher-order theory with levy solution.

- The enhancement of thickness-length ratio increases the plate natural frequency for all mechanical and electrical boundary conditions.

- The close form of the natural frequency of an anti-symmetric cross-ply with two opposite edges and other two opposite edges having an arbitrarily boundary condition had been developed based on the levy solution.

- The higher order shear deformation theories with levy solution avoids slope discontinuities at the interfaces of the composite laminated plates and predicts more accurate transverse shear and normal deformation than the first order and other higher order theories considered and gives a much better approximation to the behaviour of laminated plates.

- Shear and normal deformation effects are very significant at the interface of the actuator and laminate, which cannot be ignored while modelling laminates, especially under mechanical loading.

- Non-linear variations of displacements, stresses and strains through the thickness of the laminate are experienced along with an approximation of transverse normal deformation and transverse shear deformations.

- Inter laminar stresses have been found to occur only within a local region near the geometric boundaries of a composite laminate which are frequently referred to as a free edge effect. The high inter laminar stresses coupled with the low inter laminar strength, have been found to be of critical significance in the failure of laminated composite structures due to delamination.

\section{REFERENCES}

1. A. Bhimaraddi, L.K. Stevens, “ A Higher order theory for Free Vibration of Orthotropic, Homogeneous and laminated Rectangular Plates," Of Applied Mechanics, Vol. 51, 1984

2. A.K. Noor, "Free vibration of multilayered composite plates," of composite materials, Vol, 7, 1939.

3. A.T. Jones, "Exact natural frequencies and model function for a thick off-axis lamina," of composite materials, Vol.5, 1971.

4. C.C. Lin, W.W. King, "Free transverse vibration of rectangular Unsymmetrical laminated plates," of sound and vibration, Vol. 36(1), 1974. 
5. C.T. Sun, "Propagation of shock waves in Anisotropic composite plates," f composite materials, Vol.7, 1973.

6. C.V.J. Rao and A.K. Rao, "An exact analysis for vibration of simply supported homogeneous and laminated thick rectangular plates," of sound and vibration, Vol. 9, 1987.

7. C.W. Bert, T.L.C. Chen, "Effect $f$ Shear Deformation on Vibration of anti-symmetric Angle-ply Laminated Rectangular Plates," Of solid structure, Vol. 14, 1978.

8. C.W. Bert, B.L. Mayberry, "Free vibration of unsymmetrical laminated anisotropic plates with clamped edges," of solid and structure.

9. C.Y. China, M. K. Prabhahara, "A general Mode approach to nonlinear flexural Vibration of Laminated Rectangular Plates." Of Applied Mechanics, Vol. 45, 1978.

10. E. Hinton, "A note on a thick strip method for the free vibration of laminated plates," of earth quake engineering and structural dynamics, Vol. 4, 1976.

11. J. A. Bennett, "Nonlinear vibration of simply supported cross-ply laminated plates," of composite materials, Vol.5, 1971.

12. J. A. Bennett, “Nonlinear vibration of simply supported cross-ply laminated plates,” of Vol. 9, 1971

13. J.N. Reddy, "Free Vibration of Anti-symmetric, Cross-ply Laminated Plates Including Transverse Shear Deformation by the Finite Element Method.” Of Sound and Vibration, Vol. 66(4), 1979.

14. J.N. Reddy, "A simple Higher-order Theory for Laminated Composite Plates," Of Applied Mechanics, Vol. 51, December 1984 ,

15. J.N. Reddy and N.D. Phan, "Stability and Vibration of Isotropic, Orthotropic and Laminated Plates according to a higherorder shear deformation theory," of sound and vibration, Vol. 98(2), 1985.

16. M. Di. Sciuva, "Vibration of Simply supported thick multilayered orthotropic plates: an Evaluation of a new displacement Model," Of Sound and Vibration, Vol. 105(1), 1986.

17. M. Levinson, "Free Vibration of Simply Supported Rectangular Plates: An Exact Elasticity Solution," of sound and vibration, Vol. 98(2), 1985.

18. N.D. Phan, J.N. Reddy, “Analysis of laminated Composite Plate using Higher-order shear Deformation Theory," Int. Of numerical Methods in Engineering, Vol. 21, 1985.

19. N.S. Putcha, J.N. Reddy, "Stability and Natural Vibration Analysis of Laminated Plates by using A mixed Element based on a refined plate theory," of sound and vibration, Vol. 104(2), 1986.

20. T. kuppusamy, J.N. Reddy, “Natural Vibration of Laminated anisotropic plates,” Of sound and Vibration, Vol. 94(1), 1984.

21. R. Chandra, "Large Deflection Vibration of Cross-ply laminated plates with certain edges conditions," Of sound and vibration, Vol. 47(4), 1976.

22. R.G. Anderson, B.M. Irons and et al, "Vibration and Stability of plates using finite element," of solid and structure, Vol. 4, 1968.

23. S. Srinivas, A.K.Rao, "Vibration of simply supported thick orthotropic rectangular plates and laminates," of solids and structures, Vol.6, 1970. 